\title{
In memoriam: Sir Roger Bannister 1929-2018
}

\author{
Walter Struhal ${ }^{1}\left[\right.$. Roland D Thijs ${ }^{1} \cdot$ Anne Pavy-Le Traon $^{1} \cdot$ Gregor Wenning $^{1} \cdot$ Jean Michel Senard ${ }^{1}$
}

Received: 27 April 2018 / Accepted: 15 May 2018 / Published online: 30 May 2018

c) Springer-Verlag GmbH Germany, part of Springer Nature 2018

With great sadness The European Federation of Autonomic Societies (EFAS) reports the death of Sir Roger Bannister on March 3, 2018. Sir Roger Bannister was born on March 231929 in Harrow, England. Following his school exams he attended the University College School, London, where he obtained his undergraduate degree, followed by medical school at Oxford University.

Sir Roger Bannister was one of the best runners of his time. He became famous worldwide as the first runner to run a mile in less than 4 min (the "miracle mile"). He himself considered his fourth position and the British record at the Olympic finals for the 1500-m race and his first place at the British Empire and Commonwealth Games as well as his scientific contributions within 40 highly productive years as a neurologist as the most important landmarks in his life. Although he was one of the world's best runners of his time, he retired in 1954 from professional running to concentrate on his medical career.

In his 40 years as a neurologist he significantly advanced the field. One of his many contributions to neurology was his focus on the autonomic nervous system. He characterized autonomic dysfunctions, including acute autonomic neuropathy, and he developed tests for structured and precise measurements of the autonomic nervous system. In addition, he focused on multiple system atrophy and pure autonomic failure and broadened the spectrum of management strategies.

Sir Roger Bannister was a neurologist at St Mary's Hospital and the National Hospital for Neurology and Neurosurgery in Queen Square and initiated Autonomic Units at both hospitals. These Units continue to be leading referral centers in Western Europe (further enriched by his successor Christopher Mathias). Thus, Sir Roger Bannister also influenced clinical and scientific work on the autonomic nervous system thoughout Europe.

Among his many other commitments, he served as Chairman of the Sports Council, the ICSSPE/CIEPPS, and as Master of Pembroke College, University of Oxford. He was knighted by Queen Elizabeth II in 1975.

With the passing of Sir Roger Bannister, the field of European autonomic neurology has lost one of its giants.

The EFAS Council.
Walter Struhal

walter.struhal@tulln.lknoe.at

1 European Federation of Autonomic Societies (EFAS),

Toulouse, France 